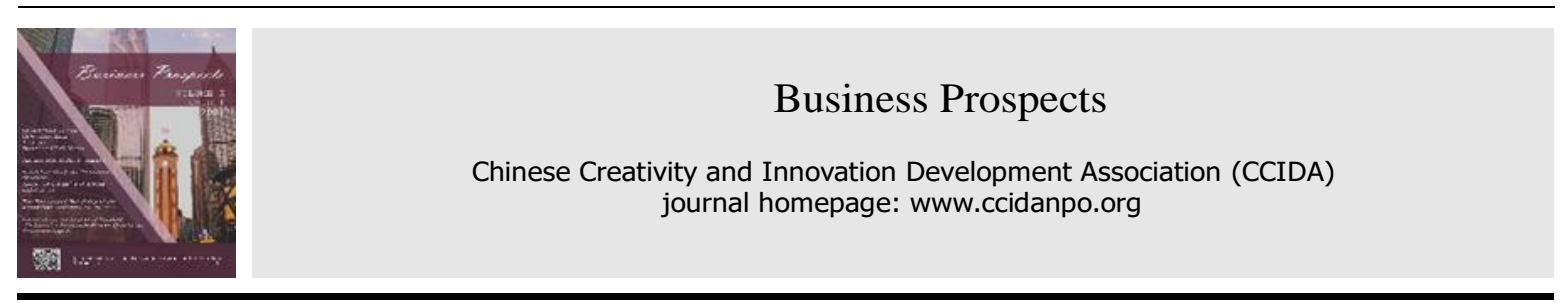

https://doi.org/10.52288/bp.27089851.2021.06.06

\title{
An Empirical Analysis of Fujian Pork Prices under African Swine Fever Based on ARIMA Model
}

\author{
Qian-Qian Song ${ }^{1}$, Jun-Xiong You ${ }^{2}$ and Meng Chen ${ }^{3, *}$ \\ ${ }^{1}$ Student of School of Management, Xiamen University Tan Kah Kee College \\ ${ }^{2}$ Associate Professor of School of Management, Xiamen University Tan Kah Kee College \\ ${ }^{3}$ Associate Professor of School of Management, Xiamen University Tan Kah Kee College \\ * Correspondence: chenmeng@xujc.com
}

Received: 2020.11.09; Accepted: 2021.05.02; Published: 2021.06.01

\begin{abstract}
This article takes the monthly data of the average pork price in Fujian Province from January 2018 to December 2019 as the research object, conducts the ARIMA model construction and analysis, and predicts the pork price in Fujian Province from January to June 2020. Results show that the pork price will have dropped slightly than before, but it is still at a relatively high level. Corresponding policy recommendations are made based on the results of the study.
\end{abstract}

Keywords: Pork Price; ARIMA Model; Forecast

\section{Introduction}

Pork is the meat that accounts for the largest proportion of China's residents' consumption. The fluctuations in pork prices continue to affect the income of farmers, but also affect the hearts of urban residents. Moreover, fluctuations in pork prices will affect the operation of the entire hog industry. Since the spread of the African swine fever epidemic in China for the first time in August 2018, pork prices across the country have risen rapidly and are still high today.

In the latest "No. 1 Document" issued by the central government in January 2020, it was specifically proposed to speed up the resumption of hog production. In order to restore the overall production capacity of live pigs to the original normal level, the government has adopted corresponding measures to list the stable production and supply of live pigs as the focus of the current national economic work as well as implement the responsibility system at all levels to ensure the supply of pork. At the same time, the government will also coordinate planning to strengthen epidemic prevention services in order to do a good job in the corresponding safety work. Since the African swine fever vaccine has not been successfully developed, the real-time tracking of the African swine fever epidemic situation must be strictly followed, and market changes must be well monitored to ensure the stability of pork supply and prices. Based on this, the monitoring and prediction of changes in pork prices are of great guiding significance to residents' lives and economic development. At present, relevant domestic researches are generally more qualitative and less quantitative (Luo and Wu, 2013), and there is no research on Fujian Province.

The article collects hog and pork price data under the influence of African swine fever epidemic in Fujian Province in 2018-2019 for two years, constructs the ARIMA model to predict the price of Fujian pork, and combines the research results to the sustainable development of pork market in Fujian province. The results of the study will be proposed as a corresponding strategy and advice

\section{Current Status of Pork Market Development under the Influence of African Swine Fever Epidemic}

\subsection{Overview of African Swine Fever}

African swine fever (ASF) is an acute, hot, and highly infectious disease with morbidity and mortality up 
to $100 \%$, which poses a great threat to the healthy development of live pigs (Wang, 2011). The disease is caused by African swine fever virus (ASFV) infection of domestic pigs and various wild boars (African wild boar, European wild boar, etc.), which first occurred in the African country Kenya and gradually spread to all countries in the world through the form of trade circulation. The African swine fever virus is an infectious virus with a high survival rate but does not infect humans (Wang, 2019).

\subsection{Impact of African Swine Fever Epidemic on Chinese Pork Market}

China raises half of the world's pigs, which has led to a high degree of concern about African swine fever introduced into China in 2018. After the outbreak of the disease in China, it spread rapidly, and the death of many pigs on the stockpile caused a decline of about $40 \%$ in Chinese slaughtered pigs in 2019. Over the past year, African swine fever has had a huge impact on China's pig industry, and it has led to a series of changes in the meat consumption market structure. As of October 25, 2019, African swine fever has occurred in 31 provinces across the country. There were more than 150 epidemics and the killing of more than 1.1 million live pigs directly caused the shortage of pork supply in China and huge losses to the national economy. As a result of the outbreak of swine fever in Africa since August 2018, the number of local sows in Fujian has dropped significantly and pig production capacity has been shrinking.

\section{Data Sources and Research Methods}

Based on the background above, the article builds the ARIMA model using EVIEWS 10.0 to predict the pork price in Fujian and to make targeted policy recommendations.

\subsection{Data Sources}

The article collects monthly data of the average pork price in Fujian Province from January 2018 to December 2019 (hereinafter referred to as "pork price". The data comes from the Fujian Agriculture and Rural Office.

Table 1. Monthly data of average pork prices in Fujian Province in 2018-19 (yuan / kg).

\begin{tabular}{ccc||ccc}
\hline date & $\mathbf{2 0 1 8}$ & $\mathbf{2 0 1 9}$ & date & $\mathbf{2 0 1 8}$ & $\mathbf{2 0 1 9}$ \\
\hline January & 25.46 & 28.00 & July & 20.40 & 29.57 \\
February & 24.98 & 26.30 & August & 21.96 & 36.88 \\
March & 22.63 & 25.76 & September & 23.24 & 39.90 \\
April & 20.78 & 26.15 & October & 23.55 & 49.12 \\
May & 19.52 & 25.90 & November & 23.52 & 50.06 \\
June & 19.83 & 27.32 & December & 23.69 & 46.84 \\
\hline
\end{tabular}

\subsection{Research Methods}

The ARIMA model is one of the time series analysis methods (Liang, 2019). The expression of the $\operatorname{ARIMA}(p, q)$ model is:

$$
y_{t}=a_{1} y_{t-1}+\cdots+a_{p} y_{t-p}+e_{t}-b_{1} e_{t-1}-\cdots-b_{p} e_{t-p}
$$

In the formula, the $(n a, n b)$ order $\operatorname{ARIMA}(p, q)$ model is denoted as ARIMA $(n a, n b)$.

In time series, stability is an important prerequisite. If the conditions in real life are unstable, it can only be stabilized and then modeled using time series. The difference equation operation of an appropriate order can be used to achieve stability, and the sequence after the difference operation can be fitted to the ARIMA $(p, q)$ model. The ARIMA $(p, d, q)$ model is the number of times $d$ ( $d$ generally does not exceed 2 in practical applications) to convert the original unstable time series into a stable time series and perform differential operations. 


\section{An Empirical Analysis of Pork Price Fluctuation in Fujian Province}

\subsection{Perform Serial Stationarity Test on the Original Data}

Since the sequence of establishing the ARIMA model must be a stationary sequence, we examine the sequence stationarity test on the original data. You can see from Table 1 that the $\mathrm{P}$ value is greater than $1 \%$. Therefore, we perform a first-order difference on the original sequence and continue to do unit root test to get Table 2. The absolute value of the $t$-statistic is greater than the absolute value of the $1 \%$ level, so the null hypothesis is rejected at the $1 \%$ significance level, which means that the first-order difference sequence of the sequence does not have a unit root and is a stationary series. The $\mathrm{P}$ value is 0.0063 , which means that $0.63 \%$ is sure to accept the null hypothesis and $99.37 \%$ is sure to reject the null hypothesis, that is, the first-order difference sequence of this sequence does not have a unit root and is a stationary sequence.

Table 2. Unit root test of original sequence.

\begin{tabular}{lcrc}
\hline \hline & & t-Statistic & Prob. $^{*}$ \\
\hline \hline Augmented Dickey-Fuller test statistic & 1.700493 & 0.9746 \\
\hline Test critical values: & $1 \%$ level & -2.669359 & \\
& $5 \%$ level & -1.956406 & \\
& $10 \%$ level & -1.608495 & \\
\hline \hline
\end{tabular}

Table 3. Unit root test after first-order difference.

\begin{tabular}{lccc}
\hline \hline & t-Statistic & Prob. $^{\star}$ \\
\hline \hline Augmented Dickey-Fuller test statistic & -2.863095 & 0.0063 \\
\hline Test critical values: & $1 \%$ level & -2.674290 & \\
& $5 \%$ level & -1.957204 & \\
& $10 \%$ level & -1.608175 & \\
\hline \hline
\end{tabular}

\subsection{Identification of ARIMA ( $p, d, q)$ Model}

Because we see that the sequence after the first-order difference is a stationary sequence, we call the price sequence first-order single integer, so $d$ is 1 . The next step is to determine $p$ and $q$. At this time, you can generally use ACF and PACF to determine the parameters.

Combining the above two figures, we can see that the autocorrelation function graph of the first-order sequence (Figure 1) has obvious tailing phenomenon, while the partial autocorrelation function graph (Figure 2 ) is truncated in phase 2, so it is considered that the first-order difference sequence follows the AR (2) process, and when PACF is tailed, the ACF is truncated after the third or fourth period, that is, to try to establish ARIMA $(2,1,3)$ and ARIMA (2 for the first-order difference sequence, 1, 4).

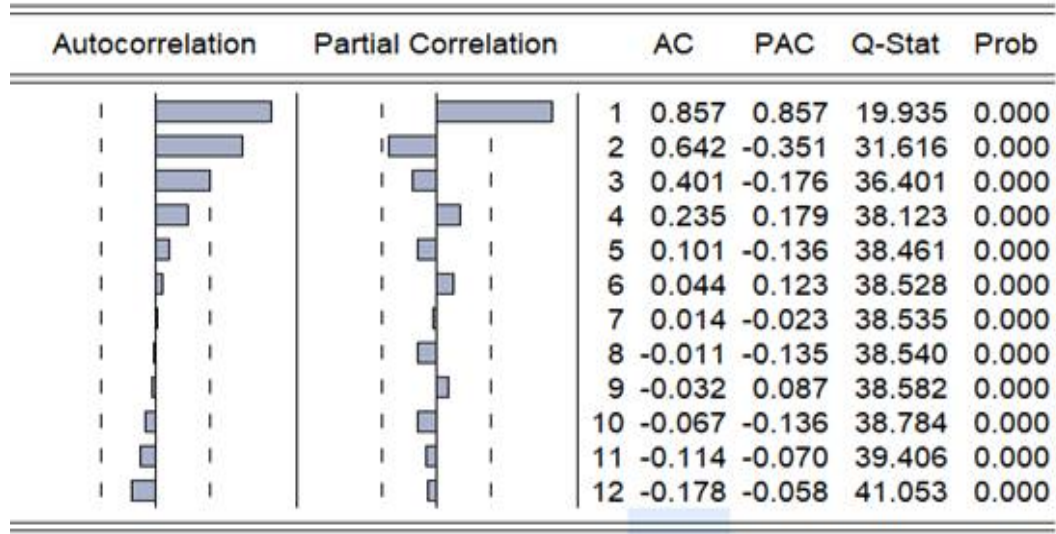

Figure 1. Autocorrelation function diagram of the first-order sequence. 


\begin{tabular}{|c|c|c|c|c|c|c|c|c|}
\hline \multicolumn{2}{|c|}{ Autocorrelation } & \multicolumn{3}{|c|}{ Partial Correlation } & \multirow{2}{*}{$\frac{A C}{0.303}$} & \multirow{2}{*}{$\frac{P A C}{0.303}$} & \multirow{2}{*}{$\frac{\text { Q-Stat }}{2.3982}$} & \multirow{2}{*}{$\begin{array}{l}\text { Prob } \\
0.121\end{array}$} \\
\hline 1 & & 1 & & 1 & & & & \\
\hline 1 & 1 & 1 & 1 & 2 & 0.176 & 0.093 & 3.2507 & 0.197 \\
\hline 1 & 1 & 1 & 1 & 3 & 0.006 & -0.079 & 3.2518 & 0.354 \\
\hline । 口 & 1 & $1 \square$ & 1 & 4 & -0.170 & -0.188 & 4.1225 & 0.390 \\
\hline 1 只 & 1 & 1 & 1 & 5 & -0.133 & -0.031 & 4.6857 & 0.455 \\
\hline 10 & 1 & 1 & 1 & 6 & -0.120 & -0.024 & 5.1702 & 0.522 \\
\hline 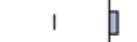 & 1 & 1 & 1 & 7 & 0.063 & 0.141 & 5.3149 & 0.622 \\
\hline 10 & 1 & $1 \square$ & 1 & 8 & -0.102 & -0.194 & 5.7175 & 0.679 \\
\hline 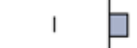 & 1 & 1 & 1 & 9 & 0.143 & 0.191 & 6.5627 & 0.683 \\
\hline 1 & 1 & 4 & 1 & 10 & 0.004 & -0.101 & 6.5634 & 0.766 \\
\hline t & 1 & 1 & 1 & 11 & -0.057 & -0.051 & 6.7217 & 0.821 \\
\hline 17 & 1 & 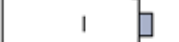 & 1 & 12 & 0.080 & 0.105 & 7.0526 & 0.854 \\
\hline
\end{tabular}

Figure 2. Partial autocorrelation function diagram.

The following modeling get:

Table 4. ARIMA $(2,1,3)$.

\begin{tabular}{crrrr}
\hline \hline \multicolumn{1}{c}{ Variable } & Coefficient & Std. Error & t-Statistic & Prob. \\
\hline \hline C & 0.846535 & 1.432253 & 0.591051 & 0.5615 \\
AR(2) & 0.197029 & 0.449058 & 0.438760 & 0.6658 \\
SA(3) & -0.028540 & 1.318952 & -0.021639 & 0.9830 \\
\multicolumn{1}{c}{ SIGMASQ } & 7.668754 & 2.067651 & 3.708921 & 0.0015 \\
\hline \hline R-squared & 0.038143 & Mean dependent var & 0.929565 \\
Adjusted R-squared & -0.113729 & S.D. dependent var & 2.887086 \\
S.E. of regression & 3.046839 & Akaike info criterion & 5.226406 \\
Sum squared resid & 176.3813 & Schwarz criterion & 5.423883 \\
Log likelihood & -56.10367 & Hannan-Quinn criter. & 5.276071 \\
F-statistic & 0.251154 & Durbin-Watson stat & 1.276140 \\
Prob(F-statistic) & 0.859514 & & & \\
\hline \hline Inverted AR Roots & .44 & -.44 & \\
Inverted MA Roots & .31 & $-.15-.26 i$ & $-.15+.26 i$ & \\
\hline \hline
\end{tabular}

Table 5. ARIMA $(2,1,4)$.

\begin{tabular}{lcccc}
\hline \hline \multicolumn{1}{c}{ Variable } & Coefficient & Std. Error & t-Statistic & Prob. \\
\hline \hline C & 0.862253 & 0.597230 & 1.443752 & 0.1651 \\
AR(2) & 0.291542 & 0.161526 & 1.804923 & 0.0870 \\
SIGMASQ & -0.546461 & 0.282037 & -1.937554 & 0.0677 \\
\hline \hline R-squared & 6.328176 & 2.731263 & 2.316941 & 0.0318 \\
Adjusted R-squared & 0.080963 & S.D. dependent var & 2.887086 \\
S.E. of regression & 2.767747 & Akaike info criterion & 5.091800 \\
Sum squared resid & 145.5480 & Schwarz criterion & 5.289277 \\
Log likelihood & -54.55570 & Hannan-Quinn criter. & 5.141465 \\
F-statistic & 1.646030 & Durbin-Watson stat & 1.374860 \\
Prob(F-statistic) & 0.212251 & & & \\
\hline \hline Inverted AR Roots & .54 & -.54 & & \\
Inverted MA Roots & .86 & $.00+.86 i$ & $-.00-.86 i$ & -.86 \\
\hline \hline
\end{tabular}




\subsection{Data Model Inspection and Prediction of Future Trends}

Comparing the above two models, the R-squared and adjusted R-squared of ARIMA $(2,1,4)$ are larger than the adjusted R-squared of ARIMA $(2,1,3)$, and the values of $\operatorname{AIC}$ and $\operatorname{SIC~ARIMA~}(2,1,4)$ are less than ARIMA $(2,1,3)$. The significance of each coefficient in the ARIMA $(2,1,4)$ equation is less than 0.1 , so we choose ARIMA $(2,1,4)$ for prediction. The predicted pork prices from January 2020 to June 2020 are as follows:

Table 6. Forecast results.

\begin{tabular}{ccc||ccc}
\hline date & price & $\begin{array}{c}\text { Predictive } \\
\text { value }\end{array}$ & date & price & $\begin{array}{c}\text { Predictive } \\
\text { value }\end{array}$ \\
\hline $18-01$ & 25.46 & NA & $19-04$ & 26.15 & 26.23 \\
$18-02$ & 24.98 & NA & $19-05$ & 25.90 & 24.68 \\
$18-03$ & 22.63 & NA & $19-06$ & 27.32 & 28.19 \\
$18-04$ & 20.78 & 23.26 & $19-07$ & 29.57 & 29.62 \\
$18-05$ & 19.52 & 21.09 & $19-08$ & 36.88 & 30.64 \\
$18-06$ & 19.83 & 20.27 & $19-09$ & 39.90 & 37.48 \\
$18-07$ & 20.40 & 21.48 & $19-10$ & 49.12 & 43.12 \\
$18-08$ & 21.96 & 22.17 & $19-11$ & 50.06 & 50.64 \\
$18-09$ & 23.24 & 23.43 & $19-12$ & 46.84 & 49.95 \\
$18-10$ & 23.55 & 24.53 & $20-01$ & & 46.41 \\
$18-11$ & 23.52 & 25.09 & $20-02$ & & 42.80 \\
$18-12$ & 23.69 & 24.34 & $20-03$ & & 43.59 \\
$19-01$ & 28.00 & 24.41 & $20-04$ & & 44.86 \\
$19-02$ & 26.30 & 29.19 & $20-05$ & & 45.70 \\
$19-03$ & 25.76 & 28.99 & $20-06$ & & 46.68 \\
\hline
\end{tabular}

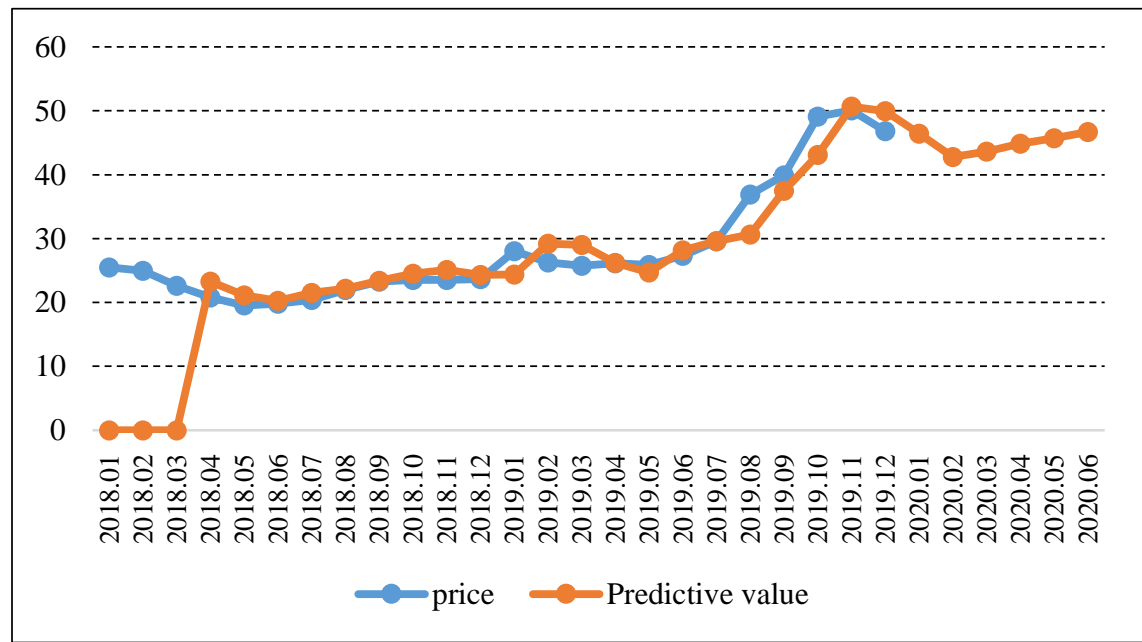

Figure 3. Trend chart of actual prices and predicted prices

It can be seen from the forecast results that the predicted value and the actual value are basically consistent. From November 2019, the price will gradually decline, and after February, the price will gradually rebound. However, the price will gradually recover after March, and it will stabilize at about 46 yuan $/ \mathrm{kg}$.

\section{Summary and Suggestions}

Taking the monthly data of average pork prices in Fujian Province from 2018 to 2019 as samples, the ARIMA model is used in this article to analyze and predict the pork in Fujian Province and to study the future price trend of Fujian pork market. If the price can be predicted in advance, the corresponding measures can be taken in advance to avoid market risks and to strive for maximum efficiency, which is also conducive to the 
stability of China's pork prices.

Under the rapid economic development, fluctuations in pork prices have always affected people's daily lives and the development of hog breeding. Based on the situation affected by the African swine fever epidemic, the following countermeasures are provided in order to promote the healthy development of the pork market and the pork in the market can be effectively guaranteed and reasonably supplied in Fujian Province:

\subsection{Improve the Early Warning System and the Information Monitoring and Early Warning Mechanism of the Whole Pork Industry Chain}

To stabilize the hog industry and pork market and ensure the stable fluctuation of pork prices, we must strengthen information monitoring and early warning from the perspective of the entire industry chain. It is extremely important to establish a complete pork industry chain information monitoring and early warning team composed of scientific research institutes, processing enterprises, wholesale markets and other comprehensive industries to strengthen market situation analysis and judgment in production, circulation, consumption, and other links. At the same time, monitoring information such as sudden disasters and epidemics (such as African swine fever) should be released in a timely manner to promote the continuous improvement of the price control system of the hog market and correctly guide the trend of the pork market ( $\mathrm{Li}$ and Ma, 2018).

\subsection{Improve the Hog Price Insurance System}

When an uncertain event like the African Swine Fever epidemic occurs, it will often cause huge losses to pig farmers, causing an imbalance between supply and demand, and causing market price fluctuations. Therefore, it is necessary to construct a new financial insurance mechanism for the hog industry under the condition of scientifically identifying the fluctuation state of pork price and combining the fluctuation range of pork price (Jia, 2013).

Improving the hog price insurance system is necessary to alleviate the problem of insufficient risk resistance of pig farms. Because hog production will face multiple risks of nature and market, the traditional policy of agricultural insurance has the effect of fractionating natural risks rather than dispersing the impact of its market risks. Hog price insurance has been running on the Chinese market since 2013, and has made active contributions to diversifying market risks. Among them, two kinds of compensation bases, "pig-to-food ratio" and "absolute price", are used to disperse market risks for pig farmers and protect the interests of farmers. It is recommended that the central government expands the scope of subsidies for pigs, and include the subsidies for hog price insurance into the content of agricultural insurance subsidies to reduce the pressure on farmers to participate in insurance. At the same time, it is required to increase the enthusiasm for insurance and practical training insurance "Bottoming" role ( $\mathrm{Li}$ and $\mathrm{Ma}, 2018)$ to promote the healthy development of the pig industry and to ensure the smooth operation of the pork market.

\subsection{Further Improve the Pork Reserve System and Use the Reserves to Smooth out the Drastic Fluctuations in the Pork Market}

Consumers and farmers are both ends of the pork market, and the government should not only ensure stable supply and prices but also safeguard the fundamental interests of farmers. The pork reserve system refers to alleviating the contradiction between supply and demand in the pork market by means of reasonable purchasing, storage and delivery. The meat reserve system has played an important role in dealing with shortterm supply shortages caused by natural disasters, public health events (such as African swine fever) and other emergencies. The results of this study suggest to improve the pork reserve system, use reserves to ease the sharp fluctuations in the pork market, and avoid the agglomeration effect in order to make the pork market a relatively stable relief (Jia, 2013; Rong et al., 2017).

\section{References}

1. Jia, Y. S. (2013). General Situation, Existing Problems and Relevant Countermeasures of Pork Reserve System in China. Meat Industry, 4: 1-5

2. Li, T. T., \& Ma, J. J. (2018). Research on Pork Price Fluctuation Based on X-12 and H-P Filter Model-A Case Study of Sichuan Province. Journal of Agricultural and Forestry Economic Management, 17(2): 177-184.

3. Liang, H. (2019). Epidemiology and Risk Factors of African Swine Fever. Rural Science and Technology, 10: 102-103. 
4. Luo, F. Q., \& Wu, C. M. (2013). Study of Theory and Application of Time Series Analysis. Journal of Liuzhou Teachers College, 24(3): 113-117.

5. Rong, Y., Li, X. F., \& Diao, G. (2017). Research on Pork Price Fluctuation Based on ARMA-GARCH Model. Heilongjiang Animal Husbandry and Veterinary Medicine, 16: 31-34.

6. Wang, Y. (2011). Fluctuations in Pork Prices in Hebei Province-Based Mathematical Model of the Law (Unpublished Master's Thesis). Hebei Province: Hebei University of Science and Technology.

7. Wang, Y. M. (2019). African Swine Fever and Its Prevention and Control Measures. Animal Health in China, 21: 3436.

(Editors: Jiaming Qiao \& Luyao Wu) 